\title{
Hospice Care Demands of Terminal Cancer Patient’ s Families in General and Hospice Units
}

Jang $A R^{*}$

Department of Nursing, Songwon University, Republic of Korea

*Corresponding author: Ae Ri Jang, Department of Nursing, Songwon University, 73 Songam-ro, Nam-gu, Gwangju 61756, Republic of Korea, E-mail: sseillerjjang79@hanmail.net

Received date: July 24, 2018; Accepted date: August 24, 2018; Published date: August 30, 2018

Copyright: @2018 Jang AR. This is an open-access article distributed under the terms of the Creative Commons Attribution License, which permits unrestricted use, distribution, and reproduction in any medium, provided the original author and source are credited.

\begin{abstract}
Background: This study attempted to provide basic data on terminal cancer patients regarding meeting their nursing needs by comparing the hospice nursing needs of general unit families, hospice families.

Method: This study was a cross-sectional descriptive study conducted on 25 families of terminal cancer patients.

Result: The finding was that total hospice nursing needs were significantly higher in the early hospice families than in the general unit families. In the sub-domains, the highest was the physical domain needs and the lowest was the spiritual domain needs.

Conclusion: Based on the results of this study, hospice nursing providers should focus on hospice nursing within 10 days after admission. Also, it is suggested that hospice nursing education programs be developed to focus on early nursing care of hospice patients.
\end{abstract}

Keywords: Hospices; Terminal cancer; Hospice care demand

\section{Trial Registration}

UMIN000029474 Registered 9 October, 2017 (retrospectively).

\section{Background}

The cancer mortality rate per 100,000 population in Korea has steadily increased, from 131.3 in 2002 to 146.6 in 2010 and to 149 in 2013 [1]. The result of the National Cancer Centre's National Recognition Survey on Dignified Death showed that from 2004 to 2008 , significantly more people responded that they would pursue hospice palliative care if the disease could not be cured by current methods, from $57.4 \%$ in 2004 to $84.7 \%$ in 2008 [2].

In 2002, the government announced plans to institutionalize hospice palliative care and then conducted the two-year Hospice Pilot Project in 2003. Subsequently, the government began providing funding to cancer-reducing medical specialist organizations in 2005 and decided to revise the Cancer Control Law, which focuses on the provision of palliative care for cancer patients, in April 2010. Following these efforts, the Ministry of Health and Welfare conducted the first pilot project for palliative medical health insurance, for one year beginning in December 2010, and has been conducting a second pilot project for health insurance since September 2011. In the future, the number of health insurance plans for hospice palliative care will also be established [3]. As the number of cancer deaths increases and the number of survey respondents who opt to use hospice palliative care surges, the National Cancer Center is constantly studying ways to revitalize hospice and palliative medical institutions; it is estimated that the number of terminal cancer patients moving from general units to hospice units will steadily increase in the future.
To date, research on the needs of domestic hospice patients has been widely conducted, including regarding inpatient family information, spiritual health, and family care expectations [4-6]. In recent years, Q methodology has been used to analyse family needs, hospice awareness, and nursing needs of families with late-stage lung cancer patients, awareness and demands of family members of childhood hospice patients, and the future direction of hospice palliative care [7-17]. Outpatient research has included family needs of hospice patients, family needs of hospital patients, and family needs of hospice patients with cancer [18-20]. Recently, community hospice needs and preference studies [21] have been carried out.

A terminal cancer patient who is judged to have no further therapeutic expectation after surgery, chemotherapy, or radiation therapy in a general unit moves to a hospice unit. Families who care for terminal cancer patients no longer want to be passive observers but active participants, and the hospice care provided to patients changes as patients move. After admission to the hospice unit, patients with terminal cancer can have difficulty communicating due to unconsciousness, weakness, and other symptoms. In this study, we aimed to identify hospice nursing needs of terminal cancer patients and their families.

We divided the terminal cancer patients into adaptation periods based on the 10 days after the patient entered the hospice unit. Specifically, they were classified as general unit families, that is, families of complex carcinoma patients with terminal cancer; early hospice families, the families of terminal cancer patients in the palliative medical clinic who stayed less than 10 days; and adapted hospice families, the families of terminal cancer patients who stayed more than 10 days in the palliative medical clinic. We intended to determine how the different types of families' hospice needs differed. 
Considering the fact that hospice developed in Korea in 1980 and there is little research on hospice, on patients' and families' transfers from general units to hospice units, and on differences in hospice nursing needs before and after patients and families adjust to hospice, there is an urgent need to study the differences in nursing needs in families with terminal cancer patients between those in general units and those in hospice units. The purpose of this study was to compare the nursing needs of general unit families, early hospice families, and adapted hospice families and then to provide basic data regarding meeting their nursing needs.

\section{Methods}

\section{Research design}

This study was a transversal descriptive research study to investigate and compare the nursing needs of common unit families with a patient who is receiving anticancer treatment without further prognosis, early hospice families with a patient with terminal cancer who is hospitalized for less than 10 days, and adapted hospice families with a patient who has terminal cancer and is hospitalized for more than 10 days.

\section{Research subjects and data collection}

The subjects of the study were conveniently collected from the families of terminal cancer patients hospitalized in the general and hospice units of $\mathrm{C}$ University Hospital located in $\mathrm{H}$ district from February 7 to August 12, 2011, and who understood and agreed to the purpose of this study. To exclude differences in the need for hospice care according to the disease, the subjects were one complex unit with no cancer-specific characteristics and the weekly call provider of the families of terminal cancer patients hospitalized at one palliative medical clinic. We distributed 135 copies of our survey; 10 had incomplete responses or the respondent stopped answering in the middle, so we used the data from a total of 125 questionnaires for the analysis. Using $G^{*}$ Power 3.1, we calculated the appropriate sample size to be used in the comparative analysis of the two groups in the descriptive study; when the effect size of the calculation result was 0.6 , the power was 0.80 , and the significance level was 0.05 , the minimum sample size was 90, so that the sample size of 125 samples was sufficient.

In order to collect the data for this study, we distributed the questionnaire after the nursing department of C University Hospital in $\mathrm{H}$ District approved our research. Before the data collection, we visited the patients' rooms with their nurses, explained the study, and distributed the questionnaire after we received written consent. After we distributed the questionnaires, we collected the data by reading the questionnaires out loud except when patients wanted to complete them directly. We visited the research units 31 times per week, and the time required to complete the questionnaire was between 10 and 40 minutes.

\section{Research tools}

Lee [22] used a total of 30 questionnaires in "A study on awareness and nursing needs of hospice" that had been modified from the questionnaire used by Ro et al. [23] to reflect Korean emotions with reference to a questionnaire by Yoon, et al. Kang and Kim [24] used a total of 22 items based on the conceptual framework applied in "The development of the research tool for the needs of cancer patients". Cho
[10] used 22 items that were revised and supplemented based on the tool developed by Kang and Kim [24] in the study "Hospice needs of patients with late-stage lung cancer and their families". Park used 30 questions that were revised and supplemented in reference to the tools developed by Ro et al. [23] and revised by Lee [22] in "Hospice recognition and nursing needs survey of cancer patients and families" [12]. In addition, Kwak [25] used 70 items in "Development of a hospice nursing satisfaction measurement tool". For validating our questionnaire, we decided to integrate all the items used in the above studies and then to revise Kwak's research tool items in consultation with five hospice nurses; these items included items from Kwak, Cho, and Park. We excluded items from "Hospice nursing should be used 24 hours a day, seven days a week" by Lee SS. and "Helping with Housework' by Lee SS. and Park. The items from "Providing as Much Family-Centered Treatment as Possible" by Kang and Kim were changed and added to "Helping a possible family to participate in care." Kwak's tool excluded questions about hospice satisfaction; we combined all the items, and from the resulting 58 items, we used a total of 54. In order to reduce the complexity of the survey, we used the patients' medical records to collect general characteristics such as sex, age, religion, education, disease name, hospitalization period, and metastasis and cancer detection year. In addition, we conducted a pilot test to ensure that the research tool was easily understood. The reliability of the tool was Cronbach's alpha $=0.935$ in the pilot test and 0.972 in the study.

\section{Data analysis method}

We analyzed the collected data using SPSS for Windows 19.0. The general characteristics of the subjects were descriptive statistics (error, percentage, mean, and standard deviation), and we analyzed their hospice nursing needs using ANOVA.

\section{Results}

\section{General characteristics of the families by group}

Among the total of 125 terminal cancer patients and their families, most $(52 / 125,41.6 \%)$ were general unit families, followed by early hospice $(31.2 \%)$ and adapted hospice $(27.2 \%)$ families. There were no differences among the three groups in terms of sex marriage, and cost of care. There were statistically significant differences in age $(\mathrm{P}<.001)$, occupation ( $\mathrm{p}=.003)$, economic level $(\mathrm{p}=.024)$, hospice perception $(\mathrm{p}<$. $001)$, family history of terminal illness $(\mathrm{p}=0.004)$, necessity of hospice care $\mathrm{p}<.001)$ and cancer detection period $(\mathrm{p}=.002)$. By age, $42.2 \%$ of the general unit family patients were age $51-60,37.8 \%$ of the early hospice family patients were age $41-50$, and $63.6 \%$ of the adapted hospice family patients were age $20-40$; the longer the hospice period, the lower the age. Forty-eight percent of the general unit family members did not know about the hospice; $46.2 \%$ and $43.6 \%$ of the early hospice family members had known about hospice or had heard about it, respectively; and $43.8 \%$ of the adapted hospice family members said hospice was well-known to them. Regarding the need for hospice care, $53.2 \%$ of the general unit families, $89.7 \%$ of the early hospice families, and $88.2 \%$ of the adapted hospice families reported that their patient family members needed hospice care.

\section{Comparison of hospice care needs by group}

As noted above, among the 125 patients, $41.6 \%$ (52) had general unit families, $31.2 \%$ (39) had early hospice families, and $27.2 \%$ (34) 
Page 3 of 5

had adapted hospice families. Overall, the family hospice nursing need ratings were 4.03 for the early hospice families, 3.91 for the adapted hospice families, and 3.64 for the general unit families $(\mathrm{p}=.002)$. Within the groups, the general unit families' needs were physical, education and referral, psychosocial, and spiritual; the early hospice families' needs were physical, psychosocial, education and referral and spiritual; and the hospice adaptation families' needs were physical, education and referral, psychosocial, and spiritual (Table 1).

\begin{tabular}{|c|c|c|c|c|c|c|}
\hline Area & $\begin{array}{l}\text { General } \\
\text { unit } \\
(n=52) M \\
\pm S D\end{array}$ & $\begin{array}{l}\text { Hospice } \\
\text { Early } \\
(n=39) M \\
\pm \text { SD }\end{array}$ & $\begin{array}{l}\text { Adapted } \\
(n=34) \quad M \\
\pm \text { SD }\end{array}$ & $\mathbf{F}$ & p & $\begin{array}{l}\text { Scheffe's } \\
\text { test }\end{array}$ \\
\hline Physical & $\begin{array}{l}3.92 \pm . \\
58\end{array}$ & $\begin{array}{l}4.38 \pm . \\
46\end{array}$ & $4.18 \pm .39$ & 9.61 & $.000^{* * *}$ & $B>A$ \\
\hline Psychosocial & $\begin{array}{l}3.58 \pm . \\
73\end{array}$ & $\begin{array}{l}4.04 \pm \\
44\end{array}$ & $3.96 \pm .55$ & 7.74 & $.001^{* *}$ & $A<B, C$ \\
\hline Spiritual & $\begin{array}{l}3.36 \pm \\
85\end{array}$ & $\begin{array}{l}3.69 \pm \\
80\end{array}$ & $3.51 \pm .65$ & 2.01 & 0.139 & \\
\hline $\begin{array}{l}\text { Educational } \\
\text { and referral }\end{array}$ & $\begin{array}{l}3.69 \pm . \\
65\end{array}$ & $\begin{array}{l}4.02 \pm . \\
57\end{array}$ & $3.99 \pm .48$ & 4.57 & $.012^{*}$ & $A<B$ \\
\hline Hospice need & $\begin{array}{l}3.64 \pm . \\
70\end{array}$ & $\begin{array}{l}4.02 \pm . \\
56\end{array}$ & $3.91 \pm .52$ & 6.68 & $.002^{* \star}$ & $A<B$ \\
\hline
\end{tabular}

Table 1: Hospice care needs of family of terminal cancer patients.

The table shows that the average hospice nursing need scores were $4.38,4.18$, and 3.92 , respectively, for the early hospice, adapted hospice, and general unit families, with a statistically significant difference $(p<0.001)$. In the psychosocial domain, there was a statistically significant difference between the early hospice, adapted hospice, and general unit families $(\mathrm{p}<0.001)$; in the spiritual domain, there were no statistically significant differences between families $(p=0.139)$. The results of the post hoc test showed that the hospice nursing needs of the early hospice families increased more than those of the general unit families.

\section{Hospice nursing need rankings}

Table 2 shows how the terminal cancer patients' families ranked their individual hospice nursing needs. The general unit families reported needing, in order, connection with the doctor, measuring patients' blood pressure and temperature and observing patients' symptoms, and encouraging positive thoughts and hope. The table provides further detail regarding the family's needs.

In general, the general unit families needed the nurses to tend to measure patient's vital signs and symptoms and to observe symptoms. The early hospice and adopted hospice families primarily needed pain management the most for their patient family members. In the psychosocial domain, the general unit families needed the nurses to listen to their patient family members opinions and monitor their emotional stability, whereas the early and adapted hospice families needed the nurses to attend to their family members' discomfort. In the spiritual realm, all families needed the nurses to encourage positive thoughts and hopes. In the education and referral area, the general unit and adapted hospice families most needed a connection with the doctor, but the adapted hospice families most needed required treatment explanations (Table 2).

\begin{tabular}{|c|c|c|c|c|c|c|}
\hline $\begin{array}{l}\text { Sectional General } \\
\text { unit }\end{array}$ & Hospice Early & Hospice Adapted & $\begin{array}{l}\text { Hospice Nursing Needs } \\
\text { Items }\end{array}$ & Total General unit & Hospice Early & Hospice Adapted \\
\hline 1 & 10 & 13 & $\begin{array}{l}\text { Measuring patients vital signs } \\
\text { and observing symptoms }\end{array}$ & 2 & 12 & 28 \\
\hline 4 & 1 & 1 & Patient pain management & 8 & 1 & 1 \\
\hline 2 & 1 & 1 & Listening to the patient & 12 & 14 & 10 \\
\hline 1 & 2 & 3 & Respect for patient's opinion & 6 & 16 & 17 \\
\hline 2 & 6 & 3 & Respect for patient's religion & 24 & 44 & 31 \\
\hline 1 & 1 & 1 & $\begin{array}{l}\text { Encourage hope and positive } \\
\text { thinking }\end{array}$ & 3 & 26 & 6 \\
\hline 1 & 1 & 2 & Connection with physician & 1 & 3 & 4 \\
\hline 2 & 3 & 1 & $\begin{array}{l}\text { Required care and caring } \\
\text { signatures }\end{array}$ & 4 & 12 & 2 \\
\hline
\end{tabular}

Table 2: Hospice nursing needs priority.

\section{Discussion}

In this study, the need for hospice care among the general unit families of terminal cancer patients was 3.64 points; in the four subdomains, the rankings were 3.92 in the physical domain, 3.69 in the education and referral domain, 3.58 in the psychosocial domain and 3.36 in the spiritual domain. Cho [10] reported, for the general unit families of late lung cancer patients, hospice nursing need scores of 3.45 points overall, 3.35 for physical needs, 3.69 for emotional needs,
3.56 for family support, and 3.53 for spiritual needs. There were no statistically significant differences between these scores and the scores in our study.

Park [12] reported an overall nursing need score among general unit families of terminal cancer patients was 3.82. In the sub-domains, the physical demand scores, emotional needs, social needs and spiritual needs were $3.82,4.27,4.20,3.82$, and 3.72 , respectively. There was no significant difference between the Park's and our group. In a study by 
Page 4 of 5

Sohn [26], general unit families of terminal cancer patients reported a hospice nursing care need score of 76.56 points (range: $22-88$ points); for the four sub-domains, the emotional support score was 3.64 , physical symptom control was 3.51, family support was 3.32, and spiritual was 3.31. In all studies, the general unit families of patients with terminal cancer ranked their patient family members' spiritual needs the lowest.

In the present study, the terminal cancer patients' families reported their hospice nursing needs as 3.98 points overall, 4.29 in the physical domain, 4.01 for psychosocial and for education and referral and 3.61 for spiritual. According to Kim [4], the information about treatment/ nursing about the patient's condition was the highest and the spiritual support was the lowest. His results were consistent with our results which showed the highest need for physical nursing and the lowest need for spiritual care.

\section{Conclusion}

In this study, a comparison of the hospice nursing needs of the families of terminal cancer patients in different units showed that the hospice unit families had significantly higher needs in all areas, significant differences in the physical, psychosocial, educational, and referral domains. Comparing the hospice nursing needs of families with terminal cancer patients in wards, the hospice nursing needs of hospice ward cancer patients were significantly higher in all domains, and there were significant differences in physical, psychosocial, education and referral domains. This suggests that patients with terminal cancer patients have the greatest need for physical nursing care. Therefore, when providing hospice care for patients with terminal cancer, priority should be given to nursing in the physical area, and efforts should be made to provide more active nursing care at the beginning of hospice admission. It is also necessary to conduct a longitudinal study on the change of nursing needs immediately after cancer diagnosis of terminal cancer patients and their families or to investigate the emotional stages of negative, distrust, depression, acceptance and compromise after terminal cancer diagnosis.

This study used some data of a master thesis, "Hospice nursing demand of terminal cancer patient and family between general ward and hospice ward', written by Ae Ri Jang.

\section{Declarations}

\section{Ethical approval and consent to participate}

All of the procedures in this study have been carried out according to the ethical standards of the Helsinki Declaration after approval from the nursing department of Chonnam National University Hospital, the nurses visited the patients and explained sufficiently about the research and obtained prior written consent.

\section{Consent for publication}

Not applicable

\section{Competing interests}

The authors declare that they have no competing interest.

\section{References}

1. http://kostat.go.kr

2. www.ncc.re.kr

3. Kim JS (2003) Status and prospects of Korea and palliative care. Paper presented at Fall Cancer Symposium. The Catholic University Hospital Cancer Center 71-77.

4. Kim CG (1988) Hospice care needs of hospitalization patient's families. Res Inst Hospice/Palliative Care 3: 13-24.

5. Min SY (1995) A study on the state of spiritual health of cancer patients. Nurs Sci 7: 127-142.

6. Lee SW, Lee EO, Huh DS, Noh KH, Kim HS, et al. (1998) The study on the medical and nursing service needs of the terminal cancer patients and their caregivers. J Korean Acad Nurs 28: 958-969.

7. Yong JS, Han SS, Hong HJ (2003) Care needs of hospice patients from the family caregivers perspective: Q-methodology. J Hosp Palliat Care 7: 47-70.

8. Lee YS (2003) Awareness and attitudes research of nurse about death and the hospice Daejeon National University.

9. Kim H (2005) A study on the attitudes of families with a terminal cancer patient to hospice. Wonkwang University.

10. Cho KM (2006) Analysis of hospice care needs of patients with terminal lung cancer and their families. Yonsei University.

11. Kim MS (2007) Comparison on the perception about hospice and the meaning of life of participants and non-participants of the hospice volunteer education program (Master's dissertation). Chonnam University.

12. Park CS (2008) The analysis on the recognition and nursing need of hospice in the cancer patient and family. Hanyang University.

13. Hong HS (2008) Perception of hospice and death among patient and family using pubic hospital in Seoul. Hanyang University.

14. Koo HY, Choi SH, Park HR (2009) Cognition and needs for hospice care among parents of children with cancer. J Korean Acad Child Health Nurs 15: 325-333.

15. Kim MR (2010) Attitudes on death and hospice palliative care of general staffs in community health center. Hanyang University.

16. Kim JH (2011) Perception of hospice among nursing university student's in chungcheong province. Hanyang University.

17. Kim BH (2011) Current and future of hospice and palliative care in South Korea. Korean J Hospice Palliative Care 14: 191-196.

18. Decker SD, Young E (1991) Self-perceived needs of primary caregivers of home-hospice clients. J Comm Health Nurs 8: 147-154.

19. Harrington V, Lackey NR, Gates MF (1996) Needs of caregivers of clinic and hospice cancer patients. Cancer Nurs 19: 118-125.

20. Newton M, Bell D, Lambert S, Fearing A (2002) Concerns of hospice patient caregivers. ABNF J 13: 140.

21. Ervin NE, Spencer GA (2005) Assessing community hospice needs and preferences. J Hospice Palliative Nurs 7: 164-173.

22. Lee SS (2000) A study on the cognition and nursing needs of the hospice. Chung-Ang University.

23. Ro YJ, Han SS, Yong JS, Song MS, Hong JU (2002) A comparison of nursing Interventions with terminal cancer patients in a hospice unit and general units. J Korean Acad Adult Nurs 14: 543-553.

24. Kang KA, Kim SJ (2005) Development of needs assessment instrument for hospice care in families of the patients with cancer. J Korean Biol Nurs Sci 7: 57-68.

25. Kwak SY (2008) Development of hospice nursing service satisfaction scale for hospice units. Keimyung University.

26. Sohn SK (2009) Needs of hospice care in families of the hospitalized terminal patients with cancer. J Korean Oncol Nurs 9: 1-6.

\section{Funding}

Not applicable 